\title{
Children developing type 1 diabetes before 6 years of age have increased linear growth independent of HLA genotypes
}

\author{
H. Elding Larsson • G. Hansson • A. Carlsson • \\ E. Cederwall • B. Jonsson • B. Jönsson • K. Larsson • \\ K. Lynch • J. Neiderud • Å. Lernmark • S.-A. Ivarsson • \\ for the DiPiS Study Group
}

Received: 30 November 2007 / Accepted: 21 May 2008 / Published online: 1 July 2008

(C) Springer-Verlag 2008

\begin{abstract}
Aims/hypothesis High birthweight and increased childhood growth are risk factors for type 1 diabetes. Relative birthweight is associated with HLA genotypes that confer a high risk of diabetes. Our aims were to test whether young children prior to clinical onset of type 1 diabetes have increased: (1) birthweight
\end{abstract}

Members of the DiPiS Study Group are listed in the Acknowledgements.

Electronic supplementary material The online version of this article (doi:10.1007/s00125-008-1074-0) contains supplementary material, which is available to authorised users.

H. Elding Larsson $(\bowtie) \cdot G$. Hansson $\cdot$ K. Lynch $\cdot \AA$. Lernmark S.-A. Ivarsson

Department of Clinical Sciences, Malmö-Paediatrics,

University Hospital MAS,

Ing. 72 Hus 91, Plan 10,

SE-205 02 Malmö, Sweden

e-mail: helena.larsson@med.lu.se

\section{A. Carlsson}

Department of Paediatrics, Lund University Hospital, Lund, Sweden

E. Cederwall $\cdot$ J. Neiderud

Department of Paediatrics, Helsingborg General Hospital,

Helsingborg, Sweden

B. Jonsson

Department of Women's and Children's Health,

Uppsala University,

Uppsala, Sweden

B. Jönsson

Department of Paediatrics, Ystad General Hospital,

Ystad, Sweden

K. Larsson

Department of Paediatrics, Kristianstad General Hospital,

Kristianstad, Sweden or birth length standard deviation scores (SDS); (2) height development SDS; or (3) BMI SDS during first 18 months of life and whether these parameters are related to HLA genotypes or mid-parental height (MPH).

Methods Birthweight, birth length, weight and height were obtained from 58 type 1 diabetes children and 155 controls matched for HLA or not in the Diabetes Prediction in Skåne study.

Results Birth length SDS corrected for MPH was increased in children developing diabetes compared with all $(p<$ $0.048)$ and with non-HLA- $(p<0.050)$ but not with HLAmatched controls. Children developing diabetes had increased height gain at 0 to 18 months of age $(p<0.005)$. Diabetic children were significantly taller from 6 to 18 months of age when correcting for MPH compared with non-HLA-matched as well as HLA-matched controls, but BMI was not increased.

Conclusions/interpretation Birth length SDS was associated with diabetes risk HLA. When corrected for MPH, children developing diabetes were taller at birth than nonHLA- but not taller than HLA-matched controls. Diabetic children had increased MPH-corrected height up to 18 months of age compared with both HLA- and nonHLA-matched controls. High-risk HLA affects prenatal growth, but other factors may explain the increased postnatal linear growth in children developing diabetes.

Keywords Birth length · Birthweight · BMI · Mid-parental height Standard deviation score $\cdot$ Type 1 diabetes
Abbreviations
DiPiS Diabetes Prediction in Skåne
MPH mid-parental height
SDS standard deviation score 


\section{Introduction}

Type 1 diabetes, a serious chronic autoimmune disease, is due to immune-mediated destruction of the pancreatic islet beta cells resulting in loss of insulin production. Children developing type 1 diabetes will depend on lifelong treatment with insulin and have a high rate of complications. The incidence of type 1 diabetes in children is increasing [1,2], especially in children below 4 years of age [3-5]. The cause of this increasing incidence is still unknown, as is the cause of the disease itself. Genetic factors, mainly HLA DR-DQ genotypes, are strong susceptibility factors [6]. However, among newly diagnosed type 1 diabetes patients only 10 to $15 \%$ have a first-degree relative with the disease [7] and the concordance rate between monozygotic twins is low $[8,9]$, underlining the importance of environmental factors.

High birthweight has been reported as a risk factor for type 1 diabetes [10-13]. We have demonstrated that children born with type 1 diabetes high-risk HLA genotypes had an increased risk of high birthweight corrected for gestational age (i.e. relative birthweight) [14]. This relationship between HLA genotypes and birthweight was recently confirmed in a study of children born to mothers with diabetes [15]. We also found that infections with fever, gastroenteritis or both during pregnancy increased the risk of high relative birthweight [16]. The possible consequences of these interactions for postnatal growth and development of type 1 diabetes are unknown.

Retrospective studies of children with diabetes have reported increased linear growth up to 7 years before onset of disease [17] as well as increased height and weight standard deviation scores (SDS) from 1 month of age [18] and increased growth in length between 1 and 3 years of age $[19,20]$. The authors of the latter study corrected growth for mid-parental height (MPH), which is known to correlate with both birthweight and birth length [21], and with postnatal growth of the child [21,22].

Increased weight and BMI in children who have developed diabetes have been reported in some studies $[18-20,23,24]$, but were not found in others [25-27]. The results in some of these studies [23, 26, 27] are complicated by the use of data collected from patients after diagnosis of diabetes, when insulin therapy had already been introduced. In the Diabetes Prediction in Skåne (DiPiS) study [14, 28, 29], children are followed from birth. As 60 children below the age of 6 years have already developed type 1 diabetes, we wanted to examine whether any of these children showed deviation in growth. Our aims were to test whether children prior to their clinical diagnosis of type 1 diabetes have increased: (1) birthweight or birth length SDS; (2) height development SDS; and (3) BMI SDS during the first 18 months of life, and whether any of these parameters are related to the HLA genotype of the child or MPH.

\section{Methods}

Population In this descriptive prospective study, we analysed data from children developing diabetes in Skåne, the most southern part of Sweden. Of 48,000 children born from September 2000 to August 2004, 60 had developed diabetes as of December 2006. These children were all born during the screening years of the DiPiS study, a populationbased prospective investigation of diabetes in children [14, $28,29]$, allowing us to select a total of 155 matched control children.

The aim of the DiPiS is to determine the positive predictive value for type 1 diabetes of genetic risk combined with islet cell autoantibody markers and to identify factors during and after pregnancy that may trigger the disease [28]. Cord blood from more than 35,000 children was genotyped for HLA and analysed for islet autoantibodies. Participating parents filled in questionnaires when the child was 2 months of age [28]. Children with increased risk of type 1 diabetes, according to a scoring based upon HLA genotype, cord blood islet autoantibodies or other risk factors such as high birthweight, infections during pregnancy and first-grade relative with diabetes, are followed annually from 2 years of age with blood samples for islet autoantibodies and questionnaires. Children developing two to three islet autoantibodies are followed every 3 months by a paediatrician, including performance of blood tests for islet autoantibodies, glucose and $\mathrm{HbA}_{1 \mathrm{c}}$. The Lund University Ethics Committee approved the DiPiS study.

Type 1 diabetic children The 60 children ( 35 boys, 25 girls) developing diabetes before the end of December 2006 (Fig. 1) were between 9 months and 5 years and 10 months old (median 2.75, range 0.75-5.84 years) at diagnosis. Seven boys and four girls developed diabetes before 18 months of age. A cord blood sample for the DiPiS study was obtained at delivery from 50 of the children. Gestational age ranged from 30 to 42 weeks, with $3 / 60$ children born prematurely (one at 30 weeks, two at 36 weeks). An additional three children were born to mothers with gestational diabetes, but none of the children had a mother with type 1 diabetes. Growth curves were available for 58/60 children.

Control children We randomly selected 155 controls, all born to non-diabetic mothers, but matched for sex, gestational week and date of birth (year and month and as near date as possible), from the 25,378 children participating in the DiPiS. Among the control children, 51 were also matched for HLA. 
Fig. 1 Children developing diabetes participating and not participating in the Diabetes Prediction in Skåne (DiPiS) study. Since children at high risk of type 1 diabetes were offered follow-up from 2 years of age, 14 children participating in the DiPiS who developed diabetes below this age were excluded from the follow-up



Growth Swedish children are regularly examined by Child Health Services (Barnavårdscentraler) before starting school. At these visits, weight and height of the child are recorded, and a growth chart completed. These growth charts, which contain birthweight, birth length, parental height and growth in infancy compared with standard Swedish normograms [30], were obtained with parental consent. Information on both parents' heights was available for $95 \%$ of the children.

$H L A$ The genotypes $H L A-D Q A 1$ and $H L A-D Q B 1$ were determined by PCR and sequence-specific probes as previously described [14, 31, 32]. HLA genotypes were available from 55 diabetic children, either from cord blood or from samples obtained at the diagnosis of diabetes. HLA$D Q A 1^{*}-B 1^{*}$ genotypes were ranked according to the risk designation criteria used to identify newborns at risk of type 1 diabetes in the DiPiS as described previously [14]. A 'risk code' was established as an arbitrary numeric description of the risk designation (Table 1).

Statistics Birthweight and birth length SDS were calculated as described [33]. Height and weight SDS after birth were calculated from the Swedish reference population [30]. MPH was calculated according to the following previously described formula [34]: SDS MPH=(height SDS of father+ height SDS of mother)/1.61. BMI SDS was calculated according to Karlberg et al. [35]. Difference from MPH was calculated as SDS birth length or height minus SDS MPH.

Parametric tests were used. If, in tests of between-group differences, unequal variances were observed, the number of degrees of freedom were corrected according to Sattherwaite [36].

In post hoc tests following ANOVA, correction for multiple testing was performed with Dunnett's test. Using multiple regression analysis we tested whether gestational age, diabetes, MPH or HLA high-risk genotypes were associated with birth length SDS, birthweight SDS and gain in height SDS. In the regression analyses, HLA risk code genotypes 3 and 4 were combined and used as a dummy variable, and compared with all other genotypes (Table 1).

We considered $p$ values less than 0.05 to be significant. In children developing diabetes before 18 months of age, values of height and BMI were not included at diabetes onset and thereafter.

\section{Results}

HLA genotypes in diabetic children Among 55 HLA-typed diabetic children, 50 (91\%) had high or moderate type 1 diabetes HLA risk, whereas five had genotypes with neutral $(n=4)$ or low $(n=1)$ risk of diabetes (Table 1).

Birth length and birthweight standard deviation scores Birth length or birthweight SDS did not differ between children who developed diabetes and either non-HLA-matched or HLA-matched controls. However, when birth length SDS was corrected for MPH, children developing diabetes had a higher score than either non-HLA-matched controls $(p<$ $0.031)$ or all controls $(p<0.048)$ (Table 2$)$. There was no 
Table $1 H L A-D Q B 1$ risk designation, genotype, risk code and HLA genotype in 55/60 children developing diabetes before 6 years of age

\begin{tabular}{|c|c|c|c|c|}
\hline \multirow[t]{3}{*}{ Diabetes risk designation $^{\mathrm{a}}$} & \multicolumn{2}{|l|}{ HLA } & \multirow[t]{3}{*}{ Risk code $^{\mathrm{c}}$} & \multirow{3}{*}{$\begin{array}{l}\text { HLA genotype } \\
n=55(\%)\end{array}$} \\
\hline & \multicolumn{2}{|l|}{$D Q A 1 *-B 1 *$ genotype } & & \\
\hline & Allele 1 & Allele 2 & & \\
\hline Very high & 0501-0201 & 0301-0302 & 4 & $28(51)$ \\
\hline High & 0301-0302 & 0102-0604 & 3 & $4(7)$ \\
\hline High & 0301-0302 & $\mathrm{X}$ & 3 & $8(15)$ \\
\hline Moderate & 0501-0201 & 0102-0604 & 2 & \\
\hline Moderate & 0501-0201 & $\mathrm{X}$ & 2 & $10(18)$ \\
\hline Neutral & 0201-0201 & 0102-0604 & 1 & \\
\hline Neutral & 0201-0201 & $\mathrm{X}, 0501-0201$ & 1 & $1(1.8)$ \\
\hline Neutral & 0201-0201 & 0301-0302 & 1 & $1(1.8)$ \\
\hline Neutral & 0102-0604 & $\mathrm{X}$ & 1 & \\
\hline Neutral & $\mathrm{X}$ & $\mathrm{X}$ & 1 & \\
\hline Neutral & 0301-0301 & 0301-0302 & 1 & $1(1.8)$ \\
\hline Neutral & 0301-0301 & 0501-0201, 0201-0201 & 1 & $1(1.8)$ \\
\hline Low & 0301-0301 & 0102-0604 & 0 & \\
\hline Low & 0301-0301 & $\mathrm{X}$ & 0 & \\
\hline Low & 0103-0603 & 0301-0302 & 0 & $1(1.8)$ \\
\hline Low & 0103-0603 & 0501-0201, 0201-0201 & 0 & \\
\hline Low & 0103-0603 & 0301-0301 & 0 & \\
\hline Low & $0103-0603,0102-0602^{\mathrm{b}}$ & $0102-0602,0102-0604^{\mathrm{b}}, \mathrm{X}$ & 0 & \\
\hline Low & 0102-0602 & 0301-0302 & 0 & \\
\hline Low & 0102-0602 & 0501-0201, 0201-0201 & 0 & \\
\hline Low & 0102-0602 & 0301-0301 & 0 & \\
\hline Low & 0102-0602 & $\mathrm{X}$ & 0 & \\
\hline
\end{tabular}

$\mathrm{X}$ is not $D Q A 1 *-B 1 * 0501-0201,0201-0201,0301-0301,0301-0302,0102-0602,0103-0603$ and 0102-0604, but includes potential homozygosity

${ }^{a}$ Risk designation criteria used to identify newborns at risk of type 1 diabetes as previously described [14]

${ }^{\mathrm{b}}$ Genotypes $D Q A 1 *-B 1 * 0103-0603 / 0102-0602,0103-0603 / 0102-0604,0103-0603 / X$ or 0102-0602/0102-0604

${ }^{\mathrm{c}}$ Risk code is an arbitrary numeric description of the risk designation

significant difference in birth length SDS corrected for MPH when comparing diabetic children with their HLAmatched controls (Table 2). The parents of children with diabetes were slightly shorter than parents of all control children $(p<0.012)$ and of HLA-matched controls $(p<0.042$; Table 2).

When analysing the multivariate association of birth length and birthweight SDS with gestational age, diabetes, MPH and HLA genotypes, both birth length SDS $(p<0.001)$ and birthweight SDS $(p<0.029)$ were positively associated with MPH (Table 3). Moreover, birth length SDS was correlated to HLA genotypes. Using the HLA genotype risk code in Table 1, a high HLA risk for diabetes was seen to be correlated to an increased birth length SDS $(p<0.010)$ (Table 3). There were no significant associations between birth length SDS or birthweight SDS and gestational age or diabetes (Table 3 ).

Height development standard deviation scores Height development SDS was calculated for the children at 3,6, 12 and 18 months of age. In children developing diabetes before 18 months of age, the height SDS at diagnosis and thereafter was not included. Height SDS in children developing diabetes did not differ from that in the nonHLA or the HLA-matched controls, except at 18 months when diabetic children were taller than non-HLA-matched controls (Electronic supplementary material [ESM] Table 1). In contrast, analysis of height gain SDS, i.e. delta height SDS, showed that the children who later developed diabetes had an increased growth rate from birth to 18 months of age compared with their HLA-matched controls, but not with non-HLA-matched controls ( $p<0.008$; ESM Table 1).

In the next analysis, height development SDS was corrected for MPH SDS to demonstrate that the children who later developed diabetes were significantly taller than all controls, non-HLA-matched controls and HLA-matched controls from 6 to 18 months of age (ESM Table 2). When testing this in a regression analysis (Table 4), the children developing diabetes had increased height velocity from 0 to 18 months of age $(p<0.005)$, controlling for gestational age, MPH SDS, HLA risk code and birth length SDS. A high MPH (i.e. tall parents) increased the height gain from birth to 18 months of age. However, HLA with risk for diabetes did not significantly affect height gain (Table 4). 
Table 2 Standard deviation scores of birth length, birthweight and BMI at birth in children developing diabetes as compared with all controls, non-HLA-matched controls and HLA-matched controls

\begin{tabular}{|c|c|c|c|c|c|c|c|c|c|c|c|}
\hline \multirow[t]{2}{*}{ Parameter } & \multicolumn{2}{|l|}{ A } & \multicolumn{2}{|l|}{ B } & \multicolumn{2}{|l|}{$\mathrm{C}$} & \multicolumn{2}{|l|}{$\mathrm{D}$} & \multirow{2}{*}{$\begin{array}{l}\mathrm{D} \text { vs } \mathrm{A} \\
p \text { value }\end{array}$} & \multirow{2}{*}{$\begin{array}{l}\mathrm{D} \text { vs } \mathrm{B} \\
p \text { value }\end{array}$} & \multirow{2}{*}{$\begin{array}{l}\mathrm{D} \text { vs } \mathrm{C} \\
p \text { value }\end{array}$} \\
\hline & All controls & $n$ & $\begin{array}{l}\text { Non-HLA- } \\
\text { matched controls }\end{array}$ & $n$ & $\begin{array}{l}\text { HLA-matched } \\
\text { controls }\end{array}$ & $n$ & Diabetes & $n$ & & & \\
\hline Birth length SDS & $\begin{array}{l}0.34 \\
(0.17 \text { to } 0.52)\end{array}$ & 155 & $\begin{array}{l}0.22 \\
(0.00 \text { to } 0.44)\end{array}$ & 104 & $\begin{array}{l}0.58 \\
(0.30 \text { to } 0.87)\end{array}$ & 51 & $\begin{array}{l}0.39 \\
(0.17 \text { to } 0.60)\end{array}$ & 58 & $<0.76$ & $<0.31$ & $<0.27$ \\
\hline Birthweight SDS & $\begin{array}{l}0.60 \\
(0.43 \text { to } 0.77)\end{array}$ & 155 & $\begin{array}{l}0.52 \\
(0.31 \text { to } 0.73)\end{array}$ & 104 & $\begin{array}{l}0.75 \\
(0.47 \text { to } 1.04)\end{array}$ & 51 & $\begin{array}{l}0.49 \\
(0.27 \text { to } 0.72)\end{array}$ & 58 & $<0.51$ & $<0.87$ & $<0.15$ \\
\hline BMI SDS birth & $\begin{array}{l}0.27 \\
(0.10 \text { to } 0.44)\end{array}$ & 155 & $\begin{array}{l}0.30 \\
(0.10 \text { to } 0.50)\end{array}$ & 104 & $\begin{array}{l}0.21 \\
(-0.15 \text { to } 0.57)\end{array}$ & 51 & $\begin{array}{l}0.09 \\
(-0.22 \text { to } 0.40)\end{array}$ & 58 & $<0.30$ & $<0.24$ & $<0.61$ \\
\hline Diff. MPH, birth & $\begin{array}{l}-0.11 \\
(-0.32 \text { to } 0.09)\end{array}$ & 147 & $\begin{array}{l}-0.18 \\
(-0.45 \text { to } 0.08)\end{array}$ & 100 & $\begin{array}{l}0.03 \\
(-0.30 \text { to } 0.36)\end{array}$ & 47 & $\begin{array}{l}0.27 \\
(-0.01 \text { to } 0.54)\end{array}$ & 55 & $<0.048$ & $<0.031$ & $<0.28$ \\
\hline SDS MPH & $\begin{array}{l}0.45 \\
(0.29 \text { to } 0.62)\end{array}$ & 147 & $\begin{array}{l}0.41 \\
(0.20 \text { to } 0.63)\end{array}$ & 100 & $\begin{array}{l}0.54 \\
(0.26 \text { to } 0.81)\end{array}$ & 47 & $\begin{array}{l}0.10 \\
(-0.11 \text { to } 0.32)\end{array}$ & 55 & $<0.012$ & $<0.042$ & $<0.013$ \\
\hline
\end{tabular}

Values are mean $(95 \% \mathrm{CI})$ unless stated otherwise

Children with diabetes had a significantly lower MPH than all controls and HLA-matched controls

Diff. MPH $=$ SDS birth length or height-SDS MPH

Diff., difference from

Body mass index standard deviation scores BMI SDS was calculated for the children at $0,3,6,12$ and 18 months of age. In children developing diabetes before 18 months the BMI SDS was not included at diabetes onset or thereafter. There were no significant differences in BMI SDS between children who later developed diabetes and non-HLAmatched or all the controls (data not shown). Comparison of BMI SDS in children who later developed diabetes with that in their HLA-matched controls showed that the children developing diabetes had a significantly lower BMI at 6 months of age $(p<0.011)$ (ESM Table 3). Furthermore, the children developing diabetes had a significantly lower BMI SDS than the Swedish standard population both at 12 months $(p<0.009)$ and at 18 months $(p<0.003)$ of age (ESM Table 3$)$.

\section{Discussion}

The major finding in our study was that children developing diabetes before 6 years of age had increased height development at 0 to 18 months of age $(p<0.005)$, when controlling for gestational age, MPH SDS, HLA genotypes and birth length SDS. In the children developing diabetes, the age-dependent trend of increased difference between the height of the child and MPH underscores the accelerated height development. Furthermore, the novel finding that birth length SDS was increased in children with high-risk HLA, regardless of whether they developed diabetes or not, confirms our previous finding [14] that HLA genotypes conferring risk of diabetes were associated with increased intrauterine growth. However, due to the limited sample, we were unable to confirm our previous finding of an association between birthweight SDS and HLA. In addition, we failed to support the hypothesis that children developing diabetes before 6 years of age had a higher birthweight SDS, but found that birth length SDS corrected for MPH was increased in diabetic children as compared with their non-HLA-matched children. The fact that this difference was not observed when compared with HLAmatched children suggests that diabetes high-risk HLA may not only affect birthweight but also birth length. Finally, in these children developing diabetes before 6 years of age, the analysis of BMI SDS suggested a trend towards a reduced rather than an increased BMI.

The present study represents all of the children who were born in Skåne County during the period September 2000 to August 2004 and subsequently developed type 1 diabetes by December 2006 [14, 28]. The 60 children developing diabetes before 6 years of age represent an incidence rate as high as about 40/100,000 children per year. In addition, a notably high number of children (11) developed diabetes before 18 months of age. Our study is therefore a population-based investigation of type 1 diabetes in children below the age of 6 years in a high-incidence cohort. Our ongoing investigation of all the children in this cohort will be needed to establish whether an accelerated height development will also be observed in those children who develop diabetes at a later age. In addition, it cannot be excluded that some of the HLA-matched controls will also develop diabetes in the future.

A potential weakness in studies on newborn children is the risk of recall bias if the values on birth length and birthweight are obtained from the parents. In the present 
Table 3 Multiple regression analysis of birth length SDS and birthweight SDS as dependent variables in relation to gestational age, diabetes, MPH and HLA genotypes with high risk of type 1 diabetes

\begin{tabular}{|c|c|c|c|c|c|c|}
\hline \multirow[t]{2}{*}{ Parameter } & \multicolumn{3}{|c|}{ Birth length SDS } & \multicolumn{3}{|c|}{ Birthweight SDS } \\
\hline & $\beta$ & $\operatorname{SE}(\beta)$ & $p$ value & $\beta$ & $\operatorname{SE}(\beta)$ & $p$ value \\
\hline Intercept & 0.87 & 1.65 & $<0.60$ & 2.80 & 1.67 & $<0.10$ \\
\hline Gestational age & -0.02 & 0.42 & $<0.64$ & -0.06 & 0.04 & $<0.17$ \\
\hline Diabetes & -0.03 & 0.18 & $<0.89$ & -0.04 & 0.18 & $<0.84$ \\
\hline MPH & 0.29 & 0.08 & $<0.001$ & 0.18 & 0.08 & $<0.029$ \\
\hline HLA risk code 3 or $4^{\mathrm{a}}$ & 0.42 & 0.16 & $<0.010$ & 0.14 & 0.16 & $<0.38$ \\
\hline
\end{tabular}

${ }^{a}$ HLA risk codes 3 or 4 were combined and used as a dummy variable $(=1)$ vs codes 0,1 and $2(=0)$

study, care was taken to obtain the birth length and birthweight data from the growth curves maintained for each child by the Child Health Services. Several epidemiological studies have reported that type 1 diabetic children have a higher birthweight [10-13]. This was not observed in the present group of children developing diabetes before 6 years of age. On the other hand, when birth length was corrected for MPH, we found that our children were taller than the controls, which is consistent with a previous finding that short birth length decreased the risk of type 1 diabetes in children up to 15 years of age [37]. The fact that birth length corrected for MPH was increased in the diabetic children compared with non-HLAmatched but not with HLA-matched controls could be due to our limited number of HLA-matched controls. Nevertheless, it is still an important novel finding, especially since we found that birth length was significantly associated with HLA genotypes.

In our study, MPH SDS were taken into consideration when we analysed intrauterine and childhood growth, since birth length, birthweight and childhood linear growth are strongly correlated with the height of the parents [21, 22, 38]. Therefore it is important to correct for MPH when analysing growth parameters. The previously described correlation between parental height and either birthweight or birth length was also confirmed in our study. We are not aware of any other study using HLA-matched controls, which seems important, as on the basis of our $[14,16]$ and other $[15,39]$ studies, it cannot be excluded that HLA is conspicuously associated with growth development not only in utero but also after delivery.

Increased height and linear growth in childhood have been reported to be a risk factor for diabetes [17-19]. In the present study we failed to confirm an increased height based on SDS in children developing diabetes. In contrast, the increased height development in relation to birth length in the diabetic children compared with HLA-matched controls suggests that children on their way to clinical diabetes may be exposed to factors that affect growth. This was also confirmed by the finding that children developing diabetes were significantly taller than expected from MPH compared with both non-HLA-matched and HLA-matched controls. We had hypothesised that HLA genotypes conferring risk of diabetes were responsible for the increased growth in children who later develop diabetes, as reported by us earlier for high-risk HLA genotypes and

Table 4 Regression analysis of SDS of height gain

\begin{tabular}{|c|c|c|c|c|c|c|c|c|c|c|c|c|}
\hline \multirow{3}{*}{ Parameter } & \multicolumn{12}{|c|}{ Height gain SDS at age } \\
\hline & \multicolumn{3}{|c|}{ 0-3 months } & \multicolumn{3}{|c|}{$0-6$ months } & \multicolumn{3}{|c|}{ 0-12 months } & \multicolumn{3}{|c|}{$0-18$ months } \\
\hline & $\mathrm{b}$ & SE (b) & $p$ value & $\mathrm{b}$ & SE (b) & $p$ value & $\mathrm{b}$ & SE (b) & $p$ value & $\mathrm{b}$ & SE (b) & $p$ value \\
\hline Intercept & -12.73 & 1.26 & $<0.001$ & -6.53 & 1.26 & $<0.001$ & -3.13 & 1.39 & $<0.025$ & -1.94 & 1.28 & $<0.131$ \\
\hline Gestational age & 0.33 & 0.03 & $<0.001$ & 0.17 & 0.03 & $<0.001$ & 0.09 & 0.04 & $<0.017$ & 0.05 & 0.03 & $<0.120$ \\
\hline MPH SDS & 0.19 & 0.06 & $<0.001$ & 0.27 & 0.06 & $<0.001$ & 0.32 & 0.07 & $<0.001$ & 0.41 & 0.06 & $<0.001$ \\
\hline Diabetic & 0.10 & 0.13 & $<0.431$ & 0.22 & 0.14 & $<0.110$ & 0.23 & 0.16 & $<0.142$ & 0.42 & 0.15 & $<0.005$ \\
\hline HLA risk code 3 or 4 & -0.01 & 0.12 & $<0.937$ & 0.01 & 0.13 & $<0.955$ & -0.04 & 0.14 & $<0.779$ & 0.04 & 0.13 & $<0.753$ \\
\hline Birth length SDS & -0.31 & 0.05 & $<0.001$ & -0.51 & 0.06 & $<0.001$ & -0.51 & 0.06 & $<0.001$ & -0.55 & 0.06 & $<0.001$ \\
\hline Adjusted $R^{2}(\%)$ & 44 & & & 38 & & & 31 & & & 41 & & \\
\hline
\end{tabular}

Children developing diabetes had increased height gain at 0-18 months of age. A high MPH (i.e. tall parents) and a low birth length SDS also increased height gain in the child. Gestational age was important for height up to 12 months of age, while diabetes risk HLA did not significantly affect the height gain 
birthweight [14]. However, our data did not support this hypothesis and indicate that factors other than high-risk HLA are responsible for this increased growth rate in children developing diabetes.

In this prospective study we examined the growth pattern of a cohort of children developing diabetes before 6 years of age compared with controls matched for HLA genotypes and corrected for MPH since this is strongly associated with the linear growth of children [21, 22, 38]. Previous studies have reported a relationship between high birthweight and both low-risk [39] and high-risk [14, 15] HLA genotypes. Our finding that birth length SDS was associated with HLA genotypes supports the hypothesis that HLA affects intrauterine growth. The association between birth length SDS and HLA is a novel finding, consistent with our previous result that HLA is associated with birthweight. The question of how HLA genotypes affect intrauterine growth remains to be answered. It is possible that they could influence the way the body handles infections, with or without subsequent temporary hyperglycaemias [16].

In conclusion, we report that children developing diabetes before 6 years of age had increased height development at 0 to 18 months of age, independently of gestational age, MPH SDS, HLA genotypes and birth length SDS. Thus, HLA did not explain the previously described height gain in infancy. We therefore speculate that height gain is related to the type 1 diabetes disease process. We also confirmed our earlier association between HLA genotypes and intrauterine growth, but were unable to confirm previous reports of increased BMI in children developing type 1 diabetes.

Acknowledgements Other co-investigators in the DiPiS study group are: C. Andersson, C. Cilio, C. Hansson, J. Heins, B. Lindberg, B. Lernmark, A. Nilsson, M. Pelkonen and A. Shalouie. We thank all the participating parents and children in the DiPiS. Our research is supported in part by the Swedish Research Council (grant no. 14064), Juvenile Diabetes Research Foundation, Wallenberg Foundation, Swedish Childhood Diabetes Foundation, Swedish Diabetes Association, Nordisk Insulin Fund, National Institutes of Health (DK26190), UMAS funds, as Terry \& Louise Gregg Diabetes in Pregnancy Award from the American Diabetes Association, Lion Club International, district 101-S, UMAS foundations and the Skåne County Council Foundation for Research and Development.

Duality of interest The authors declare that there is no duality of interest associated with this manuscript.

\section{References}

1. Green A, Patterson CC, on behalf of the EURODIAB TIGER Study Group (2001) Trends in the incidence of childhood-onset diabetes in Europe 1989-1998. Diabetologia 44(Suppl 3):B3-B8

2. DIAMOND Project Group (2006) Incidence and trends of childhood type 1 diabetes worldwide 1990-1999. Diabet Med 23:857-866
3. Dahlquist G, Mustonen L (1994) Childhood onset diabetes-time trends and climatological factors. Int J Epidemiol 23:1234-1241

4. Gardner SG, Bingley PJ, Sawtell PA, Weeks S, Gale EA (1997) Rising incidence of insulin dependent diabetes in children aged under 5 years in the Oxford region: time trend analysis. The Bart's-Oxford Study Group. BMJ 315:713-717

5. Karvonen M, Pitkaniemi J, Tuomilehto J, The Finnish Childhood Diabetes Registry Group (1999) The onset age of type 1 diabetes in Finnish children has become younger. Diabetes Care 22:1066-1070

6. Redondo MJ, Fain PR, Eisenbarth GS (2001) Genetics of type 1A diabetes. Recent Prog Horm Res 56:69-89

7. Redondo MJ, Eisenbarth GS (2002) Genetic control of autoimmunity in type I diabetes and associated disorders. Diabetologia 45:605-622

8. Kaprio J, Tuomilehto J, Koskenvuo M et al (1992) Concordance for type 1 (insulin-dependent) and type 2 (non-insulin-dependent) diabetes mellitus in a population-based cohort of twins in Finland. Diabetologia 35:1060-1067

9. Barnett AH, Eff C, Leslie RD, Pyke DA (1981) Diabetes in identical twins. A study of 200 pairs. Diabetologia 20:87-93

10. Dahlquist G, Bennich SS, Kallen B (1996) Intrauterine growth pattern and risk of childhood onset insulin dependent (type I) diabetes: population based case-control study. BMJ 313:1174-1177

11. Stene LC, Magnus P, Lie RT, Sovik O, Joner G (2001) birthweight and childhood onset type 1 diabetes: population based cohort study. BMJ 322:889-892

12. Dahlquist GG, Pundziute-Lycka A, Nystrom L (2005) Birthweight and risk of type 1 diabetes in children and young adults: a population-based register study. Diabetologia 48:1114-1117

13. Cardwell CR, Carson DJ, Patterson CC (2005) Parental age at delivery, birth order, birthweight and gestational age are associated with the risk of childhood Type 1 diabetes: a UK regional retrospective cohort study. Diabet Med 22:200-206

14. Larsson HE, Lynch K, Lernmark B et al (2005) Diabetesassociated HLA genotypes affect birthweight in the general population. Diabetologia 48:1484-1491

15. Hummel M, Marienfeld S, Huppmann M et al (2007) Fetal growth is increased by maternal type 1 diabetes and HLA DR4-related gene interactions. Diabetologia 50:850-858

16. Larsson HE, Lynch K, Lernmark B, Hansson G, Lernmark Å, Ivarsson SA (2007) Relationship between increased relative birthweight and infections during pregnancy in children with a high-risk diabetes HLA genotype. Diabetologia 50:1161-1169

17. Blom L, Persson LA, Dahlquist G (1992) A high linear growth is associated with an increased risk of childhood diabetes mellitus. Diabetologia 35:528-533

18. EURODIAB Substudy 2 Study Group (2002) Rapid early growth is associated with increased risk of childhood type 1 diabetes in various European populations. Diabetes Care 25:1755-1760

19. Bruining GJ (2000) Association between infant growth before onset of juvenile type-1 diabetes and autoantibodies to IA-2. Netherlands Kolibrie study group of childhood diabetes. Lancet 356:655-656

20. Hypponen E, Virtanen SM, Kenward MG, Knip M, Akerblom HK (2000) Obesity, increased linear growth, and risk of type 1 diabetes in children. Diabetes Care 23:1755-1760

21. Ramakrishnan U, Martorell R, Schroeder DG, Flores R (1999) Role of intergenerational effects on linear growth. J Nutr 129:544S-549S

22. Pietilainen KH, Kaprio J, Rasanen M, Winter T, Rissanen A, Rose RJ (2001) Tracking of body size from birth to late adolescence: contributions of birth length, birthweight, duration of gestation, parents' body size, and twinship. Am J Epidemiol 154:21-29

23. Knerr I, Wolf J, Reinehr T et al (2005) The 'accelerator hypothesis': relationship between weight, height, body mass index and age at 
diagnosis in a large cohort of 9,248 German and Austrian children with type 1 diabetes mellitus. Diabetologia 48:2501-2504

24. Johansson C, Samuelsson U, Ludvigsson J (1994) A high weight gain early in life is associated with an increased risk of type 1 (insulin-dependent) diabetes mellitus. Diabetologia 37:91-94

25. O'Connell MA, Donath S, Cameron FJ (2007) Major increase in type 1 diabetes: no support for the accelerator hypothesis. Diabet Med 24:920-923

26. Gimenez M, Aguilera E, Castell C, de Lara N, Nicolau J, Conget I (2007) Relationship between BMI and age at diagnosis of type 1 diabetes in a Mediterranean area in the period of 1990-2004. Diabetes Care 30:1593-1595

27. Porter JR, Barrett TG (2004) Braking the accelerator hypothesis. Diabetologia 47:352-353

28. Lernmark B, Elding-Larsson H, Hansson G, Lindberg B, Lynch K, Sjöblad S (2004) Parent responses to participation in genetic screening for diabetes risk. Pediatr Diabetes 5:174-181

29. Larsson K, Elding-Larsson H, Cederwall E et al (2004) Genetic and perinatal factors as risk for childhood type 1 diabetes. Diabetes Metab Res Rev 20:429-437

30. Wikland KA, Luo ZC, Niklasson A, Karlberg J (2002) Swedish population-based longitudinal reference values from birth to 18 years of age for height, weight and head circumference. Acta Paediatr 91:739-754

31. Ilonen J, Reijonen H, Herva E et al (1996) Rapid HLA-DQB1 genotyping for four alleles in the assessment of risk for IDDM in the Finnish population. The Childhood Diabetes in Finland (DiMe) Study Group. Diabetes Care 19:795-800

32. Sjöroos M, Iitia A, Ilonen J, Reijonen H, Lövgren T (1995) Triple-label hybridization assay for type-1 diabetes-related HLA alleles. Biotechniques 18:870-877

33. Niklasson A, Ericson A, Fryer JG, Karlberg J, Lawrence C, Karlberg P (1991) An update of the Swedish reference standards for weight, length and head circumference at birth for given gestational age (1977-1981). Acta Paediatr Scand 80:756-762

34. Ranke MB (1996) Towards a consensus on the definition of idiopathic short stature. Horm Res 45(Suppl 2):64-66

35. Karlberg J, Luo ZC, Albertsson-Wikland K (2001) Body mass index reference values (mean and SD) for Swedish children. Acta Paediatr 90:1427-1434

36. Satterthwaite FW (1946) An approximate distribution of estimates of variance components. Biomet Bull 2:110-114

37. Dahlquist GG, Patterson C, Soltesz G, The EURODIAB Substudy 2 Study Group (1999) Perinatal risk factors for childhood type 1 diabetes in Europe. Diabetes Care 22:1698-1702

38. Lundgren EM, Cnattingius S, Jonsson B, Tuvemo T (2004) Catchup growth in females born short for gestational age reduces the risk of giving birth to short-for-gestational-age infants. Horm Res 61:21-26

39. Aroviita P, Partanen J, Sistonen P, Teramo K, Kekomaki R (2004) High birthweight is associated with human leukocyte antigen (HLA) DRB1*13 in full-term infants. Eur J Immunogenet 31:21-26 